\title{
APPLICATION OF GENETIC ALGORITHM TO NETWORK FEEDER RECONFIGURATION IN RADIAL DISTRIBUTION SYSTEM.
}

\author{
Ganiyu Adedayo Ajenikoko', Olakunle Elijah Olabode ${ }^{2}$,Adefolahan Adedoyin³ \\ Babatunde Emmanuel Badmus ${ }^{4}$, Ezekiel Adewale Lawal ${ }^{5}$ \\ ${ }^{1.24,5}$ Department of Electronic and Electrical Engineering, Ladoke Akintola University of \\ Technology, P.M.B, 4000, Ogbomoso, Nigeria. \\ Corresponding Email: ajeedollar@gmail.com
}

\section{Abstract}

Distribution system being the final link in the hierarchical structure of power system is expanding daily due to exponential growth in man's activities that require power supply for its function. The fidelity of distribution system to faithfully accounts for energy obtained is highly hampered by the losses occurring at this end. It is reported that distribution system alone account for $13 \%$ of the total loss in power system. In view of this, power system engineers are faced with the challenges of minimizing the loss, reducing voltage deviation and maintaining system topology. One of the most cost effective means of doing this is network feeder reconfiguration which harnessed the feature of distribution system. Network reconfiguration re-positions the status of sectionalizing the tie-switches with a view to minimize real power losses, reduce voltage deviation and maintain network topology. This paper presents application of genetic algorithm to network feeder reconfiguration in radial distribution system. The motivation of picking GA is not unconnected with its ability to handle ill-structured optimization problems effectively. Samples of relevant papers were reviewed from 2010 till date, it was discovered that several variants of GA has emerged, alongside with hybridized version of GA. The modification(s) made and improvement on the original GA has been carefully presented. In all, the summary of improvement on GA on this concept revolved around codification methods, adaptive operators, and changes in fitness functions.It is hoped that this piece of work will be found useful to those working or intend working on distribution network reconfiguration using GA.

Keywords: Genetic Algorithm, Network Feeder Reconfiguration, Network Topology, Radial Distribution System, Sectionalizing and Tie-Switches

\subsection{Introduction}

Distribution systems serve as the final link in modern power systems which connect the electricity users to the utility company [1]. It is an interface between transmission system and the end users; saddled with sole responsibility of distributing electricity to different categories of electricity consumers and hence held accountable for energy distributed and consumed by various users $[2,3]$. The topology of distribution system is generally radial in structure which implies that the flow of power is unidirectional from the upper stream to the lower stream, although ring structure is equally possible, however the formal is preferred because of low short circuit current and easier protection co-ordination radial configuration [3]. 
Human's activities such as growing demand for electrical energy in newly constructed residential buildings, rural electrification project, urbanization and industrialization among others had placed unplanned extension on feeder route length in distribution system[2]. This in no doubt affected the fidelity of distribution system in faithfully delivering the energy meant for sale to customers.Ideally, distribution network is expected to supply electrical power to all connected customers in a manner to avoid overloading, feeder thermal overload and abnormal voltage across the line, as well as minimization of active power loss andmaintenance of radial topologysimultaneously [4]. Previous researches had shown that the reverse is the case, it was estimated thatout of totally generated electrical power, $13 \%$ of powerloss occurs at distribution system alone [3, 5-6] which is a wide margin deviation from permissible power loss of 3-6 \% in an ideal RDS[7]. Researcher [8] identified the major problems of radial distribution network (RDN) to include low reliability, low voltage and high-power loss.

Efforts to keep check on these problems arising due to the radial structure of the distribution systemboiled down to the use of capacitor placement, load feeder balancing, distributed generation and network feeder reconfiguration among others [9]. Network feeder reconfiguration is still mostly preferred since it does not require extra equipment to be installed andwith this,the approach is cost effective. Along the main feeders and lateral feeders in RDN sectionalizing switches (normally closed) and tie switches (normally open) are the two types of switches usually installed [10]. A sectionalizing switch performs the function of isolation of faulted section thereby ensuring that the healthy part of the system can still be electrically supplied. On the other hand, tie switches are designed to recover system loads that have been disconnected as a result of transfer of some loads to other supporting distribution feeders without violating operation and engineering constraints [1].

The act of opening or closing these switches or protection devices is a possible means of changing RDN topology $[11,12]$.Network feeder reconfiguration can be viewed as the process of altering feeder topological structure by careful management of the open/close status of sectionalizing and tie switches in the system under contingencies or under normal operating conditions [13]. Researcher [14] perceived distribution system reconfiguration as a combinatorial optimization problem, comprising distribution system planning, loss minimization, and energy restoration. Time to time system reconfiguration is of necessity because distribution lines show different characteristics due to the fact that each feeder in the distribution system mainly compose of residential, commercial and industrial type of loads [14]. Distribution system is reconfigured to reduce real power loss for proper load balancing and service restoration [15].

Since the inception of the concept of NFR by [16], several approaches had evolved for solving this problem. The earliest methods are the conventional/classical methods such as quadratic programming, network partitioning and heuristic nonlinear constructive techniques etc., which failed to address this problem efficiently due to radiality constraint and the discrete nature of the switches [17-19]. Artificial intelligence (AI) techniques such evolutionary algorithms (EAs), particle swarm optimization (PSO), Tabu search (TS), ant colony search (ACS) and genetic algorithms (GA) among others are the current tools for addressing this problem. These AI techniques are known to have fast computational time, deals with the problem of system size and variability of the demand [20-22].

This research paper set to investigate state of art on the application of GA to network feeder reconfiguration in radial distribution system.

\subsection{Problem Formulation in Distribution Network Feeder Reconfiguration}

The main objectives of distribution network feeder reconfiguration could be to minimize real power loss, mitigate voltage deviation and enhance the voltage profile of the 
distribution. The objective function formulation could be multi or single objective depending on what to be achieved and the likely constraints are distributed generation operation, power injection, power balance, voltage bus, radial configuration and isolation.

\subsection{Mathematical Formulation of Objective Function in DNFR}

(i). If the objective function is real power loss minimization, then it is mathematically modelled as;

$$
\operatorname{Min} . \sum_{i=0}^{n-r} r_{i} \frac{P_{i}^{2}-Q_{i}^{2}}{V_{i}^{2}}
$$

Where; $\mathrm{n}=$ number of buses, $r_{i}=$ resistance of the branch, $P_{i}=$ real power flowing through the branch, $Q_{i}=$ reactive power flowing through the branch and $V_{i}=$ voltage at the receiving end of the branch.

(ii). If the objective function is load balancing, then it is mathematically modelled as;

$$
\operatorname{Min} .(L B I)=\operatorname{Var}\left(S_{1} / S_{1}^{\max }, S_{2} / S_{2}^{\max }, S_{3} / S_{3}^{\max }, \ldots \ldots, S_{N, i} / S_{N, i}^{\max }\right)
$$

(iii). If the objective function is voltage deviation minimization, then it is mathematically modelled as;

$$
\operatorname{Min} \sum_{i=1}^{n} I_{i}^{2} R_{i}=\sum_{j=i}^{N}\left|V_{\text {rated }}-V_{j}\right|
$$

\subsection{Mathematical Formulation of Constraints in DNFR}

Generally, the DFR problem is subject to the following constraints;

(i). Voltage limit constraints on the system bus are given as;

$$
V_{i}^{\min } \leq V_{i} \leq V_{i}^{\max }
$$

Where; $V_{i}, V_{i}^{\min }$ and $V_{i}^{\max }$ are the magnitude, min and max value of voltage at bus $i$.

(ii). The constraint on feeder line current is given as;

$$
I_{i}^{\min } \leq I_{i} \leq I_{i}^{\max }
$$

Where; $I_{i}, I_{i}^{\min }$ and $I_{i}^{\max }$ are the magnitude, minimum and maximum value of current at bus $i$.

(iii). The constraint on active power flowing through feeders and branches is given as;

$$
P F_{i} \leq P F_{i}^{\max }
$$

Where, $P F_{i}$ and $P F_{i}^{\max }$ are the flowing active power of branch $i$ and its maximum allowable value.

(iv). The constraint on power output of distributed generation is given as;

$$
P_{D G} \leq P_{D G}^{\max }
$$

Where, $P_{D G}$ and $P_{D G}^{\max }$, are the power output of $i^{\text {th }}$ distribution generation and its maximum capacity

(v). The constraint on power injection is as given below;

$$
P_{S} \leq P^{\max }
$$

\subsection{Genetic Algorithm}

Genetic algorithms is a population based optimization algorithm that uses the concept of natural evolution and population genetics to search and arrive at a high quality near global solution [23]. Essential attributes of GA enhance its suitability for handling ill-structured optimization problems [24]. These essential attributes are the use pay-off (fitness or objective function) directly for the search direction, no mathematical assumption is needed and ability to discover global optimum very rapidly during searching from a population [25]. The basic genetic operators are selection, crossover, mutation and inversion. These are very essential in coding the algorithm to achieve a desired result [26]. The advantages of GA includes ability 
to handle integer or discrete variables effectively, ability to obtain global solution within shortest possible and it can be easily coded to work on parallel computers among others [27].

\subsection{Review of GA in DNFR}

Čađenović et al.(2018) presented integration of cycle-break algorithm into GA for DNFR with a view to minimize real power loss and lessen computational time. Implementation was done on three different test systems which are 70 bus, 136 bus and 880 bus system. Approximate DistFlow technique was used for the load flow analysis in this work. Cycle-break algorithm was used in initial population generation, crossover and mutation process to enhance the performance of the GA in terms of convergence rate. With this, complexity in computation effort on real distribution system was overcome. Regardless of the system sizes, system network losses and the computational time reduced appreciably, the assumption used is that the algorithm converges if global optimum solution is obtained in three consecutive evaluation epochs. Introduction oftwo novel methods for generation of spanning trees using the network AM or EC information and integration of cycle-break algorithms in the GA processes are the two major contributions to knowledge [28].

Patel, Patel and Rathor (2018) presented reduction of real power losses in DNFR with the help of GA to determine the status of the switches. IEEE 30 bus system with 5 tie switches and 32 sectionalizing switches having the total active power load of $3715 \mathrm{~kW}$ with a base voltage of $12.33 \mathrm{kV}$ was used as the test case system. Based on the analysis, after reconfiguration of the distribution network, the overall system losses decreased by $44.5 \%$ with switch numbers $7,11,34,36$ and 37 open. In addition, voltage is improved from 0.9117 p.u. to 0.9460 p.u [29].

Kanase and Gengaje (2017) proposed hybrid of fuzzy logic and genetic algorithm for NFR on IEEE 30 bus system having one feeder, 5 tie branches, and 5 tie switches. The disadvantage of long computational time associated with original GA was overcome using fuzzy logic. Multi-objective functions ofminimization of the system power loss and deviations of the node voltages were formulated. Evaluations of precise nature of these two objectives were modeled with fuzzy sets while Adaptive-GA was used to determine the network configuration that optimizes these objectives. Possible ways of improving the performance of GA was suggested which includes reduction in the length of chromosome to reduce computational time and self-tuning feature of crossover rate to improve mutation rate.Simulation results obtained proved the feasibility of the proposed algorithm. The work suggested that further studies can employ this approach on a relatively real distribution network [9].

Rao and Reddy (2017) presented GA optimization approach to get the optimal switching scheme for feeder reconfiguration on a 3-Feeder distribution network and IEEE 33bus system. The 3-feeder distribution network consists of 13 sectionalizing switches and 3 tie switches while the IEEE 33-bus system has 32 nodes, 32 sectionalizing switches and 5 tie switches. The work pointed out that the most important criterion of DFR is loss reduction, voltage profile improvement and relieving of the power lines from overloading, thesimulation results of load flow analysis and GA methodology showed that the implementation of this method leads to a significant enhancement in voltage profile and reduction in the real power loss. The work suggested that further studies can aptly avoid power flowfor each and every configuration for fitness evaluation process bytraining ANN to have the power flow data of all the feasible network configurations [30].

Rao and Reddy (2016) exploited the binary encoding and global search capability of GA to reconfigure distribution networks for loss minimization. The proposed approach was implemented on 3-feeder and 5-feeder 32-bus test systems with a set of switches (open switch) in the mesh represented in binary form. A single objective function which is network 
loss minimization was formulated and the square of its reciprocal was taken as fitness function. The system constraints are power balance, voltage magnitude constraints and limit on branch current. These were handled in the work via penalty function. The results of the proposed approach agrees perfectly with the work of other researchers that have used the same test system except the computational effort with this approach is lesser. The major contribution of the work is that the loss minimum reconfiguration using GA does not require any switch exchanges, loop power or loop current evaluation as in other methods for decision making[31].

Wazir and Arbab (2016) investigated the impact of distributed generation and test feeder reconfiguration of distribution system with a view to mitigate losses in power system and improve the voltage profile. The test system used is 33-bus radial distribution with 5 tielines, it was pointed out in the work that PSO has advantages over GA which include algorithm simplicity and ability to control convergence rate while PSO suffers from premature convergence as its drawbacks. Since GA doesn't suffer from premature convergence, this quality was sandwiched with that of PSO to form the HGAPSO algorithm. In the work, first half of the iterations are run by GA and the solutions are given as initial population of PSO, remaining iterations was run by PSO. The results showed that the optimal on/off patterns of the switches can be identified which give the minimum power loss while keeping bus voltage magnitudes within the acceptable limits. The major drawback in the work is that the DG incorporated contributed to the real power loss in the system [32].

Patel andPatel (2016) discussed reduction of real power loss in RDS via reconfiguration, by changing the status of the sectionalizing and tie switches in the system to obtain new topology. IEEE 16 bus distribution systems with 3 feeders were used as test case system. The reconfiguration was manually done to overcome its limitations, GA technique was used to determine the optimal configuration. DG was later used to reconfigure system with a view to further reduce the losses. The results show that the reconfiguration offered a promising alternative in reducing active power loss and improving the voltage profile of the network. The incorporation of GDs into system reduced the real power loss further. The limitation with the work is that the ideal of manual reconfiguration is scantly reported in literature and the procedural steps taken were tedious as in switch repositioning and further integration of DGs [33].

Sebaa et al. (2015) presented application of GAfor the reconfiguration of the distribution power system to minimize loses, improve the load-ability and the voltage profile. A typical real distribution system of 106 bus of Algeria was used as test case system. The result obtained with the proposed approach was compared with classical Branch and Bound (B\&B) method. It was observed the new topology obtained brought appreciable reduction in real power loss, improves the system loadability and enhance the system voltage profile significantly. However, the major drawback as pointed by the work is that GA exhibit long computational time before convergence and is due to searching on the unfeasible region [34]

Gurjar, Mewada, and Desai (2015) presented grid reconfiguration via GA and NSGAII. The major shortcoming of GA is that it fails to find solution when multiple objectives are to be optimized aside being too time consuming, hence NSGA-II was proposed to overcome these challenges. The use of non-dominated ranking and crowding distance by NSGA-II enable it to preserve both elitism and presents parameter less niching operator. 16 node MV, three feeder nodes and 13 load nodes were used as the test case system. A multi-objective function was formulated which includes minimization of real power loss, sum of voltage deviation and sum of current drawn from the feeders. The concept of Pareto optimality was introduced to transform the multi-objective functions into single objective function based on the fact that solutions are sorted on the non-dominance rank and the crowding distance unlike GA that uses weighting factors for transformation. The major constraints considered in the 
work are radiality, load serving and voltage constraints. Results obtained showed that the use of DG for RDS network reconfiguration is a promising alternative way of minimizing real power loss, voltage deviation and current drawn by the feeder [35]

Tapia-Juárez, Espinosa-Juárez and Graff (2015) described the development of GA as applied to reconfiguration problem of radial distribution electrical networks, taking into account the expected occurrence of voltage sags. The proposed approach was implemented on IEEE-69 bus test system having one substation, 69 buses interconnected by 73 lines, of which 5 are for tie lines and the total active and reactive loads are $3802 \mathrm{~kW}$ and $2694 \mathrm{kVA}$ respectively. The work reported that while performing the reconfiguration, voltage sags decrease depressions in several buses, but increases in some others buses; this is not unconnected to the network topology change although the system operates correctly with appreciable reduction in voltage sag [36]

Chidanandappa, Ananthapadmanabha, and Ranjith (2015) described the implementation of GA for prediction of optimum reconfiguration distribution system with multiple PV generators. A multi-objective and multi constrained problem was formulated while the load flow analysis was done via Forward backward load flow techniques considering time varying load condition. IEEE 30 bus system was used as test case system considering four load conditions and in each case, reconfiguration scheme was developed. It was observed that in several cases considered, the minimum voltage approached 1.0pu, real power losses per day reduced appreciably and minimum number of switching operations was also achieved coupled with the fact that the defined limit constraints were satisfied. The proposed approach performed satisfactorily based on the results obtained. The use of Rowlett wheel selection process and elitism in GA increases the efficiency of the algorithm [37]

Simone et al. (2014) presented reconfiguration problem of distribution networks using different demand scenarios with a view to identifying the most adequate radial topology of RDS that minimized the cost of energy losses in the network. The test systems used were 33, 70,84 and 136 buses and a real system with 417 buses. The proposed approach was a variant of original GA and it differs from the conventional GA in that it used tournament approach for the selection process and this enhanced a better value for its fitness function. An appreciable percentage reduction in cost of energy losses and computational time was observed and based on results obtained the algorithm proved to be robust, fast and efficient even when implemented on a relatively large system like 417 bus real distribution network[38].

Shamsudin et al. (2014)presented heuristic Genetic Algorithm named selection improvement in Genetic Algorithm (SIGA) in consideration of genetic operator probabilities likewise the progression of switch adjustment in DNR while satisfying the parameters constraints. The work identifies slow convergence rate, local optimum and ignoring of cooperation between populations as the major shortcoming of original GA and drawbacks were overcome by SIGA based on enhanced diversity, parents selection and improved genetic operators. IEEE 33-bus distribution system in selection of five tie switches was used as the test case system. During the analysis, the power losses were ranked in accordance to the minimum values and voltage profile improvement obtainable by the proposed algorithm. The results show that SIGA performs better than GA by giving the minimum value of power losses and enhance voltage profile improvement [39]

Guardado et al. (2014) presented network reconfiguration viaan encoding scheme for evolutionary algorithmsbased on the edge window decoder (EWD) technique, embedded in the Strength Pareto Evolutionary Algorithm 2 (SPEA2) and NSGA-II, the proposed approach was implemented on a real distribution system with 84 nodes and $531.99 \mathrm{~kW}$ of power losses in its initial configuration. The obtained results show that the proposed encoding technique enables the NSGA-II and SPEA2 algorithms to find the true Pareto-optimal solutions, which 
means that the proposed encoding technique and their genetic operators are suitable to be used in multi-objective evolutionary algorithms to solve MO-MST based problems [40].

Abubakar (2014) presented development of an optimal reconfiguration algorithm for a RDN using fast and elitist non-dominated sorting genetic algorithm (NSGA II), considering distributed generation. The proposed approach was validated using standard IEEE 33-Bus network and extended to a subsection of Zaria distribution network. A multi-objective function was formulated which include active power loss and total voltage deviationwith a view to determining the optimum locations of the tie and sectionalizing switches within the distribution network. An appreciable reduction in active power loss and voltage deviation was observed. The result revealed several feasible switching states for the various distribution systems as compared to the normal network [41]

Shamsudin et al. (2014) investigated the implementation of Improved Genetic Algorithm (IGA) to minimize the power losses in the distribution network. IGA is a variant of GA, and the modification made to original GA is improvement on selection operator. With this, the problem of long computation is reduced. The proposed approach was implemented on 33 radial bus system, a multi-objective function was formulated comprising of real power loss and voltage profile improvement. With the result of the proposed approach compared with original GA, a significant reduction in system real power and enhanced voltage profile was observed [42]

Nagy et al. (2013) presented GA based optimization technique for DNFR with a goal to reduce the network losses to barest minimum. The test case system used comprise of 3 feeders, 16 nodes, 9 switches, 3 tie switches and 6 sectionalizing switches. The feeder power was estimated based on the switch status after which GA was applied to the reconfiguration problem both at normal operation state and after fault clearance. The feeder currents, network node voltage and network losses were obtained using load flow analysis. A comparison was made between the solutions obtained using the proposed approach and the base network configuration. In all cases, the proposed approach gave lower losses than the base and the voltage profile was observed to be within the statutory limit [23]

Nuhanovic, Hivziefendic and Hadzimehmedovic (2013)addressed problem of finding the optimal network topological configuration via feeder status changing through a modified version of original GA called non-dominated sorting genetic algorithm II (NSGA II). A multi-objective problem comprising of minimization of power losses and total interruptions costs were formulated and then subjected to the network radiality voltage limits and feeder capability limits. The proposed approach was implemented on real $35 \mathrm{kV}$ distribution network with 54 nodes, 64 power lines and 26 switches. The work identified population density preservation as the major advantage of NSGA II over conventional GA which allows for uniform distribution of solutions within Pareto front. The result obtained showed the possibility of finding optimal state of the switches which will in turn produce smaller total losses and smaller total customer interruption costs. The limitation of the work was that it only encompassed active losses in calculating network losses while other losses like those due to insulation off-lines and capacitors were not accommodated [7]

Tomoiaga et al. (2013) addressed DFR using GA based on graph theory with a view to minimizing active power losses. Backward/forward sweep load flow techniques were used to determine steady state parameters of the network algorithms. The claimed merits of this approach over other distribution system load flow techniques include good accuracy, relatively small iteration number and the convergence is robust. Two different test case systems were used. These are three feeders and three loops with a total active power loss of 0.00511 p.u and the second is 1 feeder and 5 loops with total active power loss of 139.55 $\mathrm{kW}$. The methodology used spans two phases; structure checking of each configuration which represents a valid radial configuration. Results obtained showed that the proposed 
approach demonstrated good accuracy and promptness. The computational time reduced drastically. The major drawback found with the work is that the data accuracy was comparatively low [26].

Moshtaghand Ghasemi (2013) proposed NSGA-II based approach for solving distribution system reconfiguration. The special feature of NSGA-II over original GA is that it does not require weighting factors for conversion of multi-objective function into an equivalent single objective function. The test case system used are IEEE 33-bus and 69-bus distribution networks. The 33-bus system has 5- tie switches and 32 sectional switches while the 69 bus has 69 nodes, 5 tie switches and 73 branches. The result obtained with the proposed approach was compared with simulated annealing and fuzzy logic approach, the new topology obtained via open/close switch status which brought about appreciable reduction in network power loss, excellent load balancing and significant reduction in voltage drop in the system [43].

Tomoiagă et al. (2013) proposed pareto optimal reconfiguration of power distribution systems using a GA based on NSGA-II. The active power loss and system average interruption frequency index were formulated as the objective function. Weight sum approach was used to transform the multi-objective function into single objective errors caused by the conversion of different objective functions into the same measurement units; and the subjectivities caused by the introduction of weighting factors for different criteria which are the major weakeness of the earlier method were overcome with the proposed approach. The simulation results revealed that the SAIFI index was smaller in the case of existing microgrid. The comparative tests performed showed that the proposed approach demonstrated the accuracy and promptness compared to other approaches [44].

Torres et al.(2013) described GA based on edge window decoder techniques for RDS reconfiguration with a view to minimizing real power losses. A single objective function subject to apparent power and voltage magnitude as constraints was formulated. The proposed approach is different from the original GA in that it uses the edge window decoder encoding technique for network representation, building up spanning trees, and efficient enhancement of genetic operators. With this, the search space was well explored and exploited. In this work, the three phase distribution system was considered to be balanced. The proposed approach was implemented on real distribution network of 84 nodes and $531.99 \mathrm{~kW}$ of power losses in its initial configuration. The results obtained with the proposed approach were compared with Plant Growth Simulation Algorithm (PGSA), Simulated Annealing (SA), Mixed IntegerHybrid Differential Evolution (MIHDE), Ant Colony Search Algorithm (ACSA), Variable Scaling Hybrid Differential Evolution (VSHDE), genetic algorithm (GA). EWD-reconfiguration algorithm showed acceptable levels of accuracy (power losses) and computational effort [15].

Ahmed (2012) proposed an optimization technique based on GA for DNFR aimed at reducing the network losses. The proposed method was tested on IEEE network that contains 3 feeders and 16 nodes.Normal operation state, system fault condition as well as different load conditions were considered. In all cases examined, the reconfiguration took into account all constraints including AC load flow. Results obtained recorded high efficiency in power loss reduction. The authors suggested combination of network reconfiguration and capacitor placement for loss reduction in RDS as future work [45].

Zhu (2010) presented refined genetic algorithm (RGA) for optimal feeder reconfiguration of distribution network. Single objective function which is loss minimization was formulated and implemented on 16-bus which contains 3 source transformers, 13 load nodes, 3 sectional switches with total system load of $23.7 \mathrm{MW}$ and initial system power loss of $0.5114 \mathrm{MW}$. The 33-bus distribution networks consist of one source transformer, 32 load points, 5 initially-open switches with total system load of $3.715 \mathrm{MW}$ and the initial system 
power loss of $0.202674 \mathrm{MW}$. Refined genetic algorithm uses adaptive mutation which prevents premature convergence and it as well produced smooth convergence. The result of the proposed approach was compared to resistive line loss reduction. It was discovered that the proposed approach produced lesser power loss [46]

Horacio-Díaz et al. (2010) presented GA for power-energy loss cost minimization and voltage profile enhancement in RDS via capacitor placement and feeder reconfiguration simultaneously. The proposed approach was implemented on IEEE 16 bus system and a 733 bus practical distribution network, IEEE 16 bus has 3 feeders, 13 sectionalizing switches and 3- tie switches while 733 bus practical distribution has 118 switches, based on the analysis simultaneously. Taking into account, both feeder reconfiguration and capacitor placement was more effective than using only one technique. Both capacitor setting and feeder reconfiguration simultaneously generated around 10\% more energy-power losses reduction than considering them separately and hence appreciable improvement in system voltage profile was observed [47].

Swarnkar, Gupta and Niazi (2010) proposed adaptive GA to minimize real power loss in RDS. The approach was a variant of original GA. The modification made involved the use of graph theory to enhance the genetic operator to generate feasible radial topologies throughout the evolutionary process. The proposed approach was tested on IEEE 30 bus system having 37 branches and 5 tie-lines, IEEE 84-bus systemconsists of 11 feeders, 83 sectionalizing switches, and 13 tie switches and real distribution system of Brazil with 136bus system which consist of 8 feeders, 135 normally closed switches, and 21 normally open switches (136 buses, 156 branches and 13 tie-lines). The simulation results obtained for the proposed approach was compared with SA, GA and ACSA. In all cases, real power loss reduced appreciably and the computational time reduce as well. The main drawback with the work is that single objective function was formulated, however the effectiveness of the proposed approach was not verified using multi-objectives function [48].

\subsection{Discussion of Findings}

Spanning through the literatures, it was discovered that several modification(s) have been made to enhance the performance of original GA as applied to distribution network feeder reconfiguration. Table 1 itemized the variants of GA, variant attributes and enhancement made to the original GA.

Table1: State of Art on Application GA to Distribution Network Feeder Reconfiguration

\begin{tabular}{|l|l|l|l|}
\hline S/N & Variants of GA & Variant Attributes & Enhancement to Original GA \\
\hline 1.0 & $\begin{array}{l}\text { Non-dominated } \\
\text { sorting genetic } \\
\text { algorithm -II } \\
\text { (NSGA-II) }\end{array}$ & $\begin{array}{l}\text { 1.The use of non-dominated } \\
\text { ranking and crowding } \\
\text { distance } \\
\text { 2. Use of Pareto optimality } \\
\text { for transformation of } \\
\text { multiple objective functions } \\
\text { into single objective } \\
\text { function }\end{array}$ & $\begin{array}{l}\text { 1. Reduces the computational } \\
\text { time } \\
\text { 2. Inability of GA to find } \\
\text { solution when multiple } \\
\text { objectives are to be optimized } \\
\text { was overcome with the use of } \\
\text { non-dominated ranking and } \\
\text { crowding distance }\end{array}$ \\
\hline 2.0 & $\begin{array}{l}\text { Specialized genetic } \\
\text { algorithm (SGA) }\end{array}$ & $\begin{array}{l}\text { Tournament approach was } \\
\text { used for the selection } \\
\text { process }\end{array}$ & $\begin{array}{l}\text { Enhances a better value for its } \\
\text { fitness function }\end{array}$ \\
\hline 3.0 & $\begin{array}{l}\text { Selection } \\
\text { improvement in } \\
\text { Genetic Algorithm } \\
\text { (SIGA) }\end{array}$ & $\begin{array}{l}\text { Enhanced diversity, parents } \\
\text { selection and improved } \\
\text { genetic operators }\end{array}$ & $\begin{array}{l}\text { The shortcomings of GA such } \\
\text { as slow convergence rate, local } \\
\text { optimum and ignoring of } \\
\text { cooperation between }\end{array}$ \\
\hline
\end{tabular}




\begin{tabular}{|c|c|c|c|}
\hline & & & $\begin{array}{l}\text { populations was overcome with } \\
\text { the feature of SIGA }\end{array}$ \\
\hline 4.0 & $\begin{array}{l}\text { Edge window } \\
\text { decoder techniques } \\
\text { based GA }\end{array}$ & $\begin{array}{l}\text { Edge-widow was used for } \\
\text { network representation, } \\
\text { building up spanning trees, } \\
\text { and efficient enhancement } \\
\text { of genetic operators }\end{array}$ & $\begin{array}{l}\text { It enhanced the exploration and } \\
\text { exploitation of search space and } \\
\text { guaranteed global optimum } \\
\text { solution }\end{array}$ \\
\hline 5.0 & $\begin{array}{l}\text { Adaptive genetic } \\
\text { algorithms(AGA) }\end{array}$ & $\begin{array}{l}\text { It involves the use of graph } \\
\text { theory to enhance the } \\
\text { genetic operator to generate } \\
\text { feasible radial topologies }\end{array}$ & $\begin{array}{l}\text { 1. Efficient Mesh Check } \\
\text { 2. Reduction of computational } \\
\text { Burden }\end{array}$ \\
\hline 6.0 & $\begin{array}{l}\text { Refined genetic } \\
\text { algorithm (RGA) }\end{array}$ & $\begin{array}{l}\text { It used adaptive mutation as } \\
\text { against normal mutation } \\
\text { process in original GA }\end{array}$ & $\begin{array}{l}\text { 1. Prevents premature } \\
\text { convergence } \\
\text { 2. It as well produced smooth } \\
\text { convergence }\end{array}$ \\
\hline 7.0 & $\begin{array}{l}\text { Improved Genetic } \\
\text { Algorithm (IGA) }\end{array}$ & $\begin{array}{l}\text { Selection operator in } \\
\text { original GA was improved }\end{array}$ & $\begin{array}{l}\text { The problem of long } \\
\text { computational time was } \\
\text { reduced with the improved } \\
\text { selector operator }\end{array}$ \\
\hline
\end{tabular}

To prevent the problems of premature convergence and long computational time due to selection operator associated with the original GA as applied to distribution network feeder reconfiguration, several hybridized version of GA has been proposed. The details and performance enhancement provided by these hybridized algorithms are as summarized in the Table 2 below;

Table 2: State of Art on Hybridized Version of GA as applied to Distribution Network Feeder Reconfiguration

\begin{tabular}{|l|l|l|l|}
\hline S/N & $\begin{array}{l}\text { Name of Hybridized } \\
\text { Version of GA }\end{array}$ & $\begin{array}{l}\text { Attributes of GA } \\
\text { hybridized Algorithm }\end{array}$ & Enhancement to original GA \\
\hline 1.0 & $\begin{array}{l}\text { Cycle-break and genetic } \\
\text { algorithms (CBGA) }\end{array}$ & $\begin{array}{l}\text { Excellent initial } \\
\text { population generation, } \\
\text { crossover and mutation } \\
\text { process }\end{array}$ & $\begin{array}{l}\text { 1.Enhancement of } \\
\text { convergence rate } \\
\text { 2.Complexity in } \\
\text { computational effort on real } \\
\text { distribution system reduced } \\
\text { drastically }\end{array}$ \\
\hline 2.0 & $\begin{array}{l}\text { Fuzzy logic and genetic } \\
\text { algorithm (FLGA) }\end{array}$ & $\begin{array}{l}\text { Used Fuzzy set for } \\
\text { modelling of multi- } \\
\text { objective functions }\end{array}$ & $\begin{array}{l}\text { 1. Reduction in the length of } \\
\text { chromosome, this reduced } \\
\text { computational time } \\
\text { 2. Self-tuning feature of } \\
\text { crossover rate, this improved } \\
\text { mutation rate }\end{array}$ \\
\hline 3.0 & $\begin{array}{l}\text { Particle swarm } \\
\text { optimization (PSO)and } \\
\text { Genetic Algorithm } \\
\text { (HGAPSO) }\end{array}$ & $\begin{array}{l}\text { PSO simplicity and } \\
\text { enhanced ability to } \\
\text { control convergence rate } \\
\text { was combined with } \\
\text { global convergence } \\
\text { characteristics of GA }\end{array}$ & $\begin{array}{l}\text { 1. Premature convergence } \\
\text { was eliminated } \\
\text { 2. Initial running was done } \\
\text { with GA while its solution id } \\
\text { fed to PSO to obtain global } \\
\text { solution }\end{array}$ \\
\hline
\end{tabular}


The bar-chat below illustrates the country distribution of reviewed articles within the review years. It is obviously reflect, that Nigerian researchers have done little in the area of distribution network feeder reconfiguration despite the huge real power losses and severe voltage deviation on Nigerian distribution system. India has the leading papers in this field of knowledge followed by Mexico, Malaysia, Egpyt and Bosnia respectively.

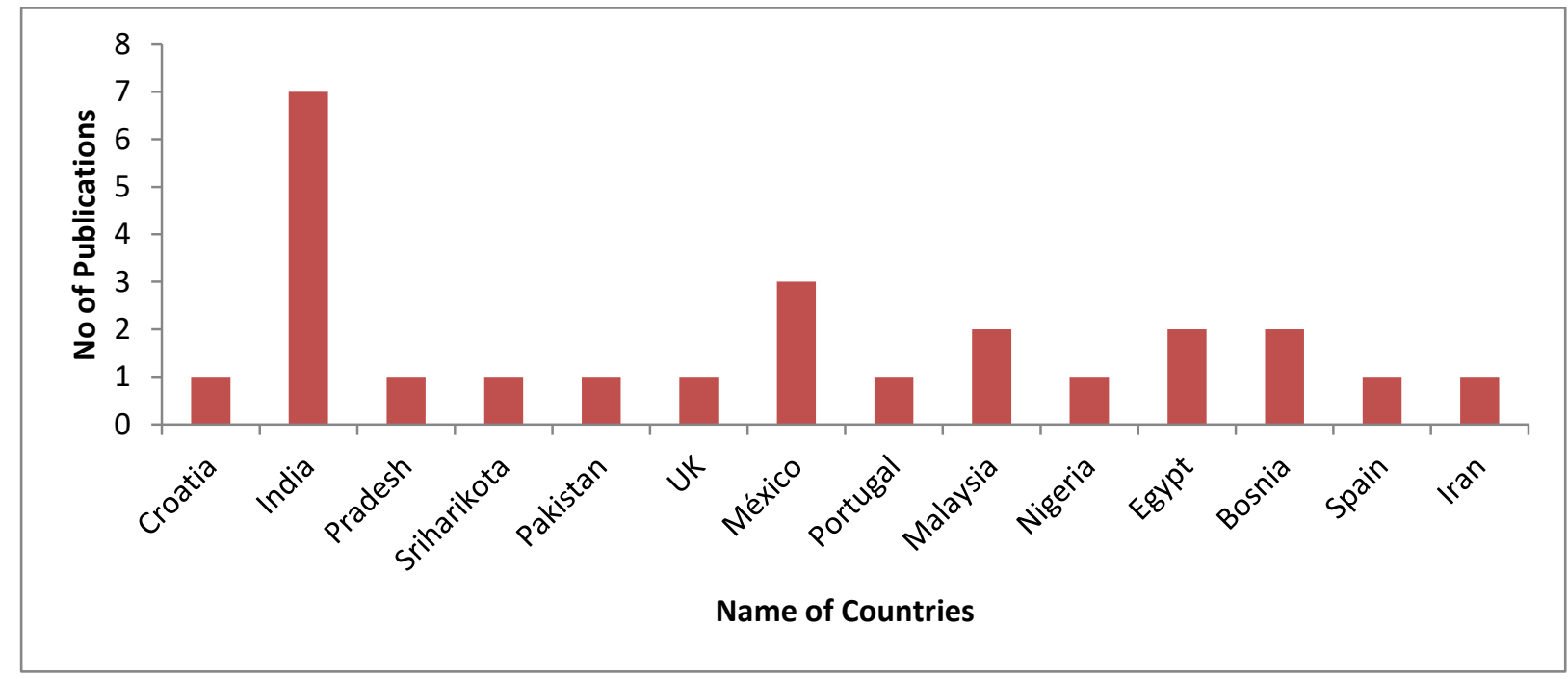

Figure1: Shows the number of publications within the review year on country basis

In addition, the number of papers reviewed per year is as illustrated by the bar-chart shown in Figure 2 below. From Figure 2, highest relevant publications on this concept was published in year 2013, also, year 2014 had a good number of relevant publications on this concept while the least number of paper relevant papers were published in 2012 and none was found relevant in 2011 as depicted in the bar chart illustrated in Figure 2.

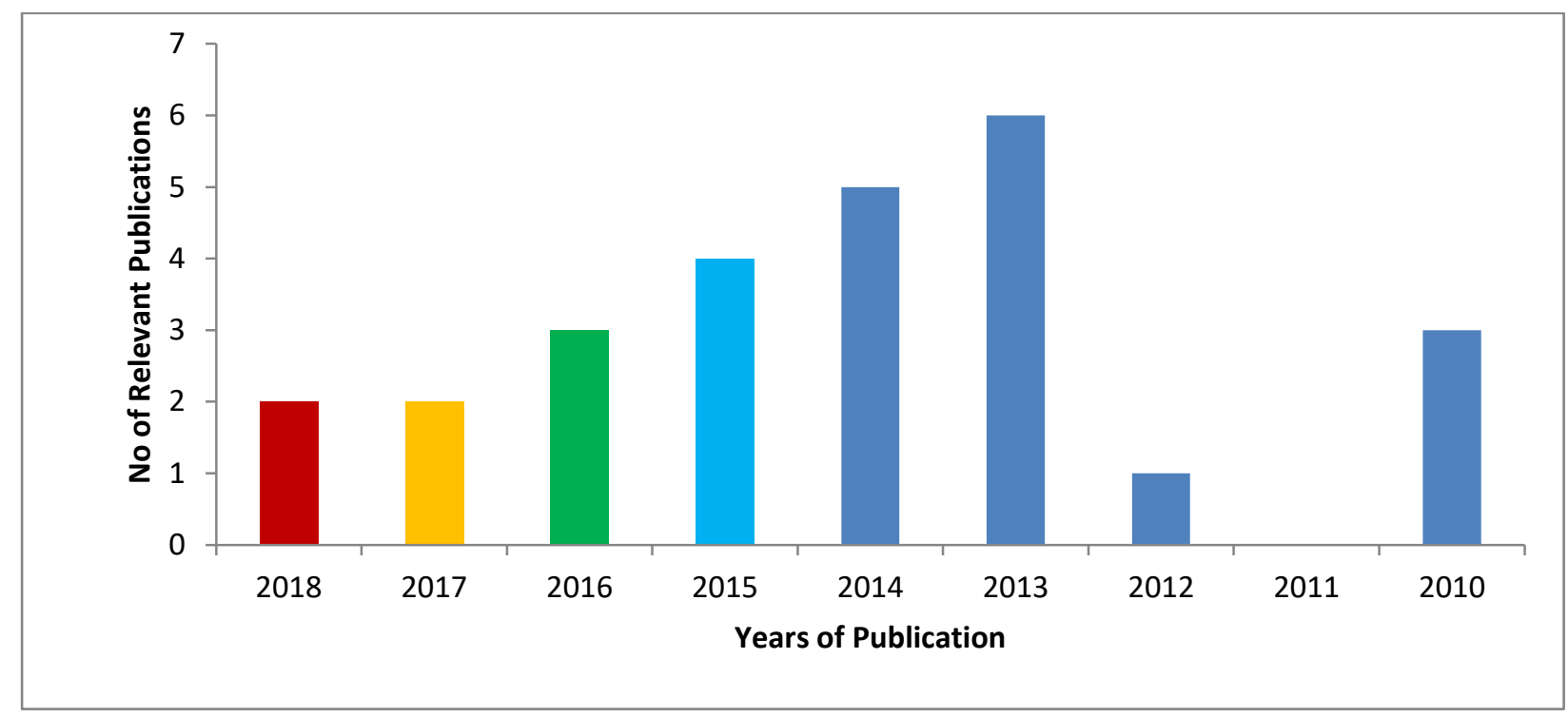

Figure 2: Number of relevant publications within the reviewed years

\subsection{Conclusion}

This paper presents application of Genetic Algorithm to network feeder reconfiguration in radial distribution system. Samples of relevant open accessible literatures were reviewed from 2010 till date on this concept, it was discovered that the earlier work of 
Merlin and Back had witnessed a great improvement both in terms of methodology and implementation tools. Based on the papers reviewed, with a view to finding state of art on this concept, the initial scope of network feeder reconfiguration via changing the status of sectionalizing and tie-switches has expanded holistically. The state of art on this concept now accommodates the use of distributed generation (DG) which was found to have reduced real power losses appreciably if correctly placed.

Intensive search through the reviewed papers showed that several variants of GA has emerged for handling network feeder reconfiguration with superior performance over the original GA. Findings revealed that weaknesses of GA necessitate the development of hybridized version of GA and most of the hybridized version of GA used trade-off approaches as clearly reported in the reviewed section. It is important to point out that the concept of reliability analysis had been successfully integrated into the scope of network feeder reconfiguration in radial distribution system.

\section{References}

[1] Sedighizadeh, M. Esmaili, M and Mahmoodi, M. M. (2017).Reconfiguration of distribution systems to improve reliability and reduce power losses using imperialist competitive algorithm.Iranian Journal of Electrical \& Electronic Engineering, Vol. 13, No. 3, pp.287-302.

[2] Ade-Ikuesan, O. O., Okakwu, I. K., Osifeko, M. O., and Olabode, O. E (2018). Investigation of electric power losses on primary distribution feeder: a case study of Sango - Ota distribution company, Ogun State, Nigeria. International Journal of Applied Engineering Research, Volume 13, Number 7, pp. 5000- 5003.

[3] Sureshkumar, K and P. Vijayakumar (2015). Distribution network reconfiguration for loss minimization using differential evolution algorithm.ARPN Journal of Engineering and Applied Sciences, Vol. 10, No. 7, pp.2861-2866.

[4] Carcamo-Gallardo, A, Garcia-Santander, L and Pezoa, J. E, (2009). Greedy reconfiguration algorithm for medium-voltage distribution networks. IEEE Transactions on Power Delivery, 24(1), pp.328-335.

[5] Baran, M. and Wu, F. (1989). Network reconfiguration in distribution systems for loss reduction and load balancing. IEEE Transaction on Power Delivery, Vol. 4, No. 2, pp. 1401-1407.

[6] Guidelines for Energy Audit in Power Systems, CEA, New Delhi May 1992.

[7] Nuhanovi'c, A., Hivziefendi'c, J., and Hadzimehmedovi'c, A. (2013).Distribution network reconfiguration considering power losses and outages costs using genetic algorithm.Journal of Electrical Engineering, Vol. 64, No. 5, pp. 265-271.

[8] Samarghandi, S. and Sarhangzadeh, M (2017). Reconfiguration and capacitor allocation in radial distribution systems with a new Independent loop identification method. Leonardo Electronic Journal of Practices and Technologies, Issue 31, pp. 23 44.

[9] Kanase, A.B., and Gengaje, S.R. (2017).Fuzzy-genetic approach for reconfiguration of electric distribution network. Journal of Emerging Technologies and Innovative Research,Volume 4, Issue 12, pp. 60-66.

[10] Ziari, I., Ledwich, G., Ghosh, A. and Platt, G.(2012). Integrated distribution systems planning to improve reliability under load growth. IEEE Transactions on Power Delivery, Vol. 27, pp. 757-765.

[11] Bernardona, D.P., Garcia, V.J, Ferreira, A.S.Q and Canha, L.N. (2009).Electric distribution network reconfiguration based on a fuzzy multi-criteria decision making algorithm. Electric Power Systems Research,doi:10.1016/j.epsr.2009.04.012. 
[12] Kumar, K.K., Ramana, N.V., Kamakshaiah, S., and Nishanth, P.M (2013).State of art for network reconfiguration methodologies of distribution system.Journal of Theoretical and Applied Information Technology, Vol. 57 No.1, pp.25-40.

[13] Moshtagh, J. and Ghasemi, S.(2013).Optimal distribution system reconfiguration using non-dominated sorting genetic algorithm (NSGA-II).Journal of Operation and Automation in Power Engineering, Vol. 1, No. 1, 13-21.

[14] Chakravorty, J (2012).Network reconfiguration of distribution system using fuzzy controlled evolutionary programming. International Journal of Engineering Science\& Advanced Technology, 2(2), $176-182$.

[15] Torres, J. Guardado, J.L, Rivas-Dávalos, F., Maximov, S. and Melgoza, E (2013). A genetic algorithm based on the edge window decoder technique to optimize power distribution systems reconfiguration. Electrical Power and Energy Systems 45, 28-34.

[16] Merlin, A. and Back, H. (1975). Search for a minimal loss operating spanning tree configuration in an urban power distribution system. Proceedings of $5^{\text {th }}$ Power system computation conference (PSCC), Cambridge, UK, pp. 1-18.

[17] Baran, M.E, Wu, F.F.(1989). Network reconfiguration in distribution systems for loss reduction and load balancing. IEEE Trans Power Del; 4(2):1401-1407.

[18] Niknam T. (2011). An efficient multi-objective HBMO algorithm for distribution feeder reconfiguration. Expert Syst Appl., 38:2878-87.

[19] Niknam T, Azadfarsani E, Jabbari M. (2012). A new hybrid evolutionary algorithm based on new fuzzy adaptive PSO and NM algorithms for distribution feeder reconfiguration.Energy Convers Manage, 54:7-16.

[20] Gomez F, Carneiro S, Pereira JLR, Vinagre M, Garcia P, Araujo L. A new heuristic reconfiguration algorithm for large distribution systems. IEEE Trans Power Syst, 20(3):1373-8.

[21] Schmidt, H.P., Ida, N., Kagan, N., Guaraldo, J.C.(2005).Fast reconfiguration of distribution systems considering loss minimization. IEEE Trans Power Syst., 20(3):1311-9.

[22] Gomez, F., Carneiro, S., Pereira, J.L.R., Vinagre, M., Garcia, P., Araujo, L. (2006). A new distribution system reconfiguration algorithm approach using optimum power flow and sensitivity analysis for loss reduction. IEEE Trans Power Syst., 21(4):161623.

[23] Nagy, S. A., Ibrahim, I. S., Ahmed, M. K., Adail, A. S., and Soliman, S.(2012).Network reconfiguration for loss reduction in electrical distribution system using GA.Arab Journal of Nuclear Science and Applications, 46(1), 78-87

[24] Li, F., Song, Y. H., Morgan, R., and Cheng, D. T. (1994).Genetic algorithms in electric power system optimization. Proc Adaptive Computing in Engineering Design and Control, p. 77-83.

[25] Srinivasan, D., Wen, F., Chang, C. S., and Liew,. A. C. (1996) A survey of applications of evolutionary computing to power systems, ISAP'96.

[26] Tomoiaga, B., Chindris, M., Sumper, A., Villafafila-Robles, R. and Sudria-Andreu, A. (2013). Distribution system reconfiguration using genetic algorithm based on connected graphs. Electric Power Systems Research, Vol.104, pp.216-225.

[27] Wang, J., Luo, A., Qi, M., and Li, M. (2014).The Improved Clonal Genetic Algorithm \& Its Application in Reconfiguration of Distribution Networks.

[28] Čađenović, R., Jakus, D., Sarajčev, P., and Vasilj, J (2018). Optimal distribution network reconfiguration through integration of cycle-break and genetic algorithms,Energies, 11, 1-18. 
[29] Patel, A.G., Patel, C and Rathor, S (2018). Distribution network reconfiguration to reduce power loss and improve voltage profile, Innovation and Technology Summit, pg 1-13.

[30] Rao,K. K. S. V. V.P and Reddy, V. C V (2017).Impact of distribution feeder reconfiguration for loss reduction on bus voltages -a perspective. International Journal of Advance Research, Ideas and Innovations in Technology, pp.137-143.

[31] Rao,K.K.S.V.V and Reddy, V. C. V (2016). Distribution Feeder Reconfiguration for minimum losses using Genetic Algorithms, International Research Journal of Engineering and Technology,Vol.3 Issue: 08, pp. 1897-1903.

[32] Wazir, A. and Arbab, N (2016). Analysis and optimization of IEEE 33 bus radial distributed system using optimization algorithm, Journal of Emerging Trends in Applied Engineering,Vol. 1, No. 2, pp.18-21.

[33] Patel, A.G. andPatel, C (2016). Distribution network reconfiguration for loss reduction. International Conference on Electrical, Electronics, and Optimization Techniques, pp. 1-6.

[34] Sebaa, K., Henini, N. and Tlemani, A. (2015) Restructuration of distribution power system using Genetic Algorithms. In: UPEC2015, Stoke on Trent, UK, 1-4 September 2015.

[35] Gurjar, S.J., Mewada, U., and Desai, P.V (2015).Smart Grid Reconfiguration Using Genetic Algorithm and NSGA-II, International Journal of Engineering Research and Development, pp 49-55.

[36] Tapia-Juárez, R., Espinosa-Juárez, E and Graff, M. (2015). Reconfiguration of distribution systems to reduce voltage sags by using genetic algorithms, Faculty of Electrical Engineering, Universidad Michoacana de San Nicolás de Hidalgo Morelia, México, pp. 1-7.

[37] Chidanandappa. R., Ananthapadmanabha, T. and Ranjith.H.C (2015). Genetic algorithm based network reconfiguration in distribution systems with multiple DGs for time varying loads, Procedia Technology 21, $460-467$.

[38] Simone S. F. S, Romero, R., Pereira, J., and Saraiva, J. T. (2014). Specialized genetic algorithm of chu-beasley applied to the distribution system reconfiguration problem considering several demand scenarios, pp. 2-23.

[39] Shamsudin, N. H., Omar, N. F., Sulaima, M. F., Jaafar, H. I. and Kadir, A.F.A. (2014). International Journal of Engineering and Technology,Vol 6 No 2, pp.12471258.

[40] Guardado, J. L., Rivas-Davalos, F., Torres, J., Maximov, S. and Melgoza, E.(2014). An Encoding Technique for Multi-objective Evolutionary Algorithms Applied to Power Distribution System Reconfiguration, The Scientific World Journal, pp. 1-9.

[41] Abubakar, A.S (2014). Development of an optimal reconfiguration algorithm for radial distribution electrical power networks: a case study of Zaria distribution network, A Thesis Submitted to the Department of Electrical and Computer Engineering of AhmaduBello University, pp. 1-101.

[42] Shamsudin, N.H., Omar, N.F., Abdullah, A.R., Sulaima, M.F., Abidullah, N.A and Jaafar, H.I.(2014). An improved genetic algorithm for power losses minimization using distribution network reconfiguration based on re-rank approach, Research Journal of Applied Sciences, Engineering and Technology 8(8): 1029-1035.

[43] Moshtagh, J.andGhasemi, S. (2013).Optimal Distribution System Reconfiguration Using Non-dominated Sorting Genetic Algorithm (NSGA-II), Journal of Operation and Automation in Power Engineering, Vol. 1, No. 1, pp. 12-21. 
[44] Tomoiagă, B., Sumper, C.A., Sudria-Andreu, A and Villafafila-Robles, R (2013). Pareto Optimal Reconfiguration of Power Distribution Systems Using a Genetic Algorithm Based on NSGA-II, Energies, 6, 1439-1455.

[45] Ahmed, S. (2012). Thesis submitted in fulfillment of the requirement for the degree of Master of Science in Electrical Engineering Department, Faculty of Engineering - AlAzhar University, pp. 1-120.

[46] Zhu, J.Z. (2010). Optimal reconfiguration of electrical distribution network using the refined genetic algorithm. Electric Power Systems Research 62, 37-42.

[47] Horacio, D.R., Ildefonso H. V., Raúl, S. H., and Romina O. R (2010). Ingeniare. Revista chilenade ingeniería, Vol. 18, No. 1, pp. 144-153.

[48] Swarnkar, A., Gupta, N and Niazi, K. R(2010). Minimal Loss Configuration for Large-Scale Radial Distribution Systems using Adaptive Genetic Algorithms, 16th National Power Systems Conference, pp. 647- 652. 